\title{
Research on Jingdezhen's Competitiveness in the Cultural Industry
}

\author{
Aiping Zhou \\ (Jingdezhen Ceramic Institute, Jingdezhen ,Jiangxi,333000)
}

\author{
Keywords: Jingdezhen; Cultural Industry; Competitiveness; Porcelain Culture; Tea Culture
}

\begin{abstract}
In the current era, culture is an important part of China's overall national strength and it is also the main force for strengthening comprehensive national strength. Faced with the main contradiction between the people's ever-increasing material and cultural needs and the unbalanced and uneven development proposed at the party's $19^{\text {th }}$ National People's Congress, the development of cultural industries is particularly important. The cultural industry of the "Millennium Capital" Jingdezhen, as an important part of the Chinese culture, must also comply with the needs of the development of the times and improve the competitiveness of its own industries. Starting from the relevant definition of the cultural industry and the competitiveness of the cultural industry, this paper combines the development of Jingdezhen porcelain culture and tea culture, studies the advantages, disadvantages, opportunities, and challenges of Jingdezhen's competitiveness in the cultural industry, and tries to provide corresponding countermeasures to improve its industrial competitiveness.

Located in the northeast of Jiangxi Province, Jingdezhen is known as the "Porcelain Capital in the World" and is also one of the 24 historical and cultural cities announced by the State Council in the first batch. It is also the main export destination for the ancient "Silk Road" [1]. The cultural industry in Jingdezhen is most prominent with its porcelain culture and tea culture. In recent years, Jingdezhen's cultural industry has developed rapidly with the state's emphasis on culture and its unique geographical advantages, historical advantages, and policy advantages, and its cultural competitiveness is constantly improving. However, there are still some problems that affect its healthy development. Therefore, the study of the advantages, disadvantages and development strategies of Jingdezhen's cultural industry will undoubtedly allow Jingdezhen to have a clear understanding of its own competitiveness in the cultural industry, so that the inadequacies will be eliminated and the industrial competitiveness will be better improved.
\end{abstract}

\section{What Is The Cultural Industry And Competitiveness Of The Cultural Industry?}

Culture is a very broad concept. It is the sum of all material wealth and spiritual wealth that human beings can create. The culture of a country or a nation does not only include the history, geography, customs, and customs of the country or nation, but also includes the country's residents' habits, production and lifestyle, degree of behavioral conduct, literary arts, modes of thinking, and values. Cultural Industry. The cultural industry was first mentioned in the book "The Dialectics of Enlightenment" co-edited by Horkheimer and Adorno. The English name is Culture Industry. It is literally translated as the culture industry, but it can also be translated as a cultural industry. The cultural industry is actually a new industry developed under the background of the globalization model. It is generally considered by the world to be "the sunrise industry or the gold industry in the 21st century" [2]. China's cultural industry includes the following categories: Products that are constantly created and produced in order to meet people's spiritual needs with culture as the main content; The auxiliary production activities that must be made to enable the production of cultural products;Tool production activity that can be regarded as the carrier of the cultural products or can produce cultural products; Production activities that must use special production equipment in order to promote the production of cultural products.

Competitiveness of the Cultural Industry. The competitiveness of the cultural industry is created to meet the needs of the cultural industry and the conditions for supply. It reflects the development capabilities that the cultural industry can achieve. Cultural industry competitiveness actually has two meanings. One layer refers to the competitiveness of the cultural industry in the 
cultural market, and the other refers to the ability of a cultural industry to disseminate or promote a certain culture. Under the current background of global economic globalization, the dissemination or promotion of a certain culture must be carried out in the market through market-based means. It can also be reflected through the competitiveness demonstrated by such cultural products. It can also be adopted by others. This kind of cultural identity products reflect the competitiveness of the product. [3]

\section{Introduction to Jingdezhen's Cultural Industry}

Jingdezhen has a well-known name of "the source of porcelain, the hometown of tea", the "porcelain culture and tea culture" has become the most representative cultural industry in the entire city of Jingdezhen. Jingdezhen should take advantage of its own good resources to better explore the inner meaning of the "porcelain and tea art" culture, so as to promote the sustainable development of Jingdezhen's economy and effectively enhance the competitiveness of Jingdezhen's cultural industries.

Ceramic Culture Industry. The ceramic culture industry is the most representative of the cultural industries in Jingdezhen. With the support of the state and the government, Jingdezhen has now established a number of national and provincial porcelain cultural industry demonstration bases. At present, there are rich and varied types of ceramics produced by Jingdezhen, not only involving art and porcelain and daily-use porcelain, but also high-tech porcelain, architectural porcelain and many other types. The cultural market of porcelain is also more active. The major brands are exquisite, such as "Franz", "Jingde Burning" and "Zhen Ru Tang" [4].

Tea Culture Industry. The Jingdezhen tea art culture industry is still at its initial stage, and most of them still remain only in the fine processing and deep processing of tea. "Yueyu Live Tea", "Floating Yaoxianzhi" and "Yaoli Yakyu" are famous brands of Jingdezhen tea. But compared with West Lake's "Longjing", Yunnan's "Pu'er", Fujian's "Da Hong Pao" and other tea, the Jingdezhen tea art culture industry still lacks long-term planning and operation mode.

\section{The SWOT Analysis of Jingdezhen's Cultural Industry Competitiveness}

Although the cultural industry competitiveness of Jingdezhen has its own unique advantages, it also has its shortcomings; there are opportunities for its historical development, but it also faces many challenges. In order to have a clearer and more thorough understanding of the competitiveness of Jingdezhen's cultural industries, the author uses the SWOT analysis method to analyze the competitiveness of Jingdezhen's cultural industries in detail.

Strengths. It has huge reputation. Jingdezhen is a famous porcelain capital of China and foreign countries. When it comes to Jingdezhen, people immediately think of porcelain. Since ancient times, the porcelain culture of Jingdezhen is rich in culture, and the scope of communication is also very wide. Porcelain is very rich in decoration, and many porcelains are enduring. Implications are deep. Although Jingdezhen is not the only city in China that produces porcelain, its porcelain culture is the only one in the world. [5]There are dozens of ancient sites in Jingdezhen. There are many historical and cultural landscapes related to porcelain. There are sites of ten porcelain workshops in the past and many urban alleys rich in history and culture. Jingdezhen has been engaged in tea art since ancient times. On the Silk Road, it exports porcelain and tea. There are many celebrities. Jingdezhen ceramic celebrities can also be said to be the world's most, whether it is professors, or senior arts and crafts talent, or have won national, provincial and municipal masters honors are very many.

Weaknesses. The level of economic development presents disadvantages: The cultural industry continues to develop as the level of economic development increases, and the two are in a positive proportion. In recent years, although the total volume of ceramics and tea culture industry in Jingdezhen has increased rapidly, which has led to the growth of the local economy, because the industry is relatively single, the gap between its economic development and other developed provinces in China remains large. The economic development level of Jingdezhen has, to a certain 
extent, restricted the development of its ceramic and tea art cultural industries. The overall strength of the cultural industry presents disadvantages: Jingdezhen has a relatively small scale of cultural industries, an unbalanced industrial structure, a relatively low productivity of cultural products, and a low level of marketization. People's consumption levels are not high enough. Therefore, the overall strength of Jingdezhen's cultural industry is relatively weaker.

Opportunities. National macro policy: Since the reform and opening up, especially after the party's $19^{\text {th }}$ National Congress, China has increasingly valued the development of China's cultural industry. The "structural reforms on the supply side" and the "Belt and Road Initiative" proposed by Chairman Xi Jinping have provided favorable conditions for the development of the cultural industry in Jingdezhen.Strong demand for cultural consumption: After the outbreak of the global financial crisis in 2008, the level of global cultural consumption has not been constrained. On the contrary, there has been a rapid increase. At the same time, with the rapid development of China's economic strength and the significant improvement of China's international status, people both at home and abroad are curious about objects that have a strong Chinese culture. This background provides an opportunity for accelerating the development of the cultural industry in Jingdezhen[6].

Threats.Competition from other parts of the country: Over the past few years, China has issued many policies on the reform of the cultural system. Therefore, the cultural industries in many regions have taken advantage of the situation. The cultural industry has become a pillar industry of China's national economy. The process of marketization of the cultural industry will be faster and faster, and the degree of marketization will also be higher and higher. The cultural industry has already become one of the important strategies for the development of provinces and cities across the country. If Jingdezhen cannot formulate a scientific and rational development strategy, its cultural industry will be in a disadvantageous position in the fiercely competitive market. The lack of talents in the cultural industry: With the accelerating development of information technology, the development of the cultural industry needs constant innovation and adapts to the pace of the times. The talent structure of the cultural industry must meet higher requirements. This requires the introduction of talents in the current cultural industry, so that its talent team continues to move toward high-end. At present, most of the ceramic and tea art cultures in Jingdezhen attract middle-aged and older people, but young, technically-minded people are not interested in these cultures. Therefore, there is a serious shortage of talents in the cultural industry in Jingdezhen.

\section{Analysis of Countermeasures to Promote Cultural Industry Competitiveness of Jingdezhen}

In the face of SWOT analysis, we need to integrate the overall situation of the current Jingdezhen cultural industry, develop advantages, overcome disadvantages, seize opportunities, and face challenges.

Play the leading role of cultural heritage. The Jingdezhen cultural industry should make full use of Jingdezhen's precious material cultural heritage, promote the improvement of the porcelain industry and the tea industry structure, and promote the close mingling of the porcelain culture and tea industry with the economy. Constantly increase innovative cultural elements and new era characteristics, take the road of winning with quality, and provide impetus for the development of cultural and creative industries.

Utilize the government's superior policy. Jingdezhen's cultural industry must seize the opportunity of "the Belt and Road" policy and carry out comprehensive reform and innovation. Under "the Belt and Road" policy, Jingdezhen's cultural industry must gradually move toward the international and domestic markets, strengthen the vitality of the cultural industry, continue to innovate, abolish the old development system, and increase the space for the development of the cultural industry. It is necessary to enhance Jingdezhen's top-level design ideas for the development of the "Belt and Road" cultural industry and formulate concrete action plans for the development of cultural industries. In addition, the government must also provide a better platform and service for the development of the cultural industry, appropriately reduce the unnecessary links in the administrative approval of the cultural industry, shorten the time, and provide real-time data for the cultural industry, such as market conditions and cultural industry development, providing 
convenient conditions for the cultural industry in Jingdezhen and the countries along the "Belt and Road" route, and actively promoting the "going out" of the cultural industry in Jingdezhen.

Establish a "china, tea art" cultural tourist area. Jingdezhen is a thousand-year-old town with rich tourism resources. Therefore, the porcelain culture and tea culture cultural tourism routes can be carefully planned to allow Jingdezhen's tourists to experience Jingdezhen's ancient and splendid porcelain culture and tea culture, inspiring purchase desires of tourists from all over the world, and achieving a positive interaction between porcelain culture, tea culture production and tourism consumption. With the rise of "farmhouse fun", tourists can carry out interesting activities such as picking tea leaves, ploughing fields, and making their own porcelain. It is necessary to seize the rich cultural heritage and pleasant natural environment of Jingdezhen itself, as well as the unique charm of porcelain and tea culture, so that visitors can experience the cultural charm of Jingdezhen at close range.

Strengthen the training of modern specialized personnel. Talent is the fundamental and core of enterprise development. Nowadays, with the development of informatization, the competitiveness of the cultural industries in Jingdezhen must be heightened. It is necessary to increase the promotion of informationization and introduce specialized talents with high technology. The Jingdezhen government can set up related majors in colleges and universities. Enterprises can also cooperate with universities and colleges and universities to jointly cultivate such high-tech specialized talents and reserve reserves for the development of enterprises. Meanwhile, it is necessary to increase capital investment in the introduction of talents, and actively introduce foreign high-end talent in this area, so as to better promote the development of the cultural industry in Jingdezhen and enhance the competitiveness of its cultural industries.

\section{Acknowledgements}

Jiangxi University Humanities and Social Science Research Project (2015), Research on Contemporary Art Ceramic Price Evaluation System Based on AHP Method, Project Number: GL1572

\section{References}

[1] H.F Shen, Q Guo and J.W Yu. Journal of Jingdezhen University, 2013, 28(2):25-28.

[2] B.F Liu. Business Economy, 2017(4):49-50.

[3] Q Guo, T.T Liu. Journal of Shandong University of Science and Technology (Social Science Edition), 2017, 19(5):61-67.

[4] Y Yan and L Guo. Knowledge Economy, 2015(10): 54-55.

[5] L.L Liu. Journal of Chongqing University of Science and Technology (Social Science Edition), 2017(9):40-42.

[6] Z.H Rao and J. Xiao Jiangxi's Cultural Industry the Belt and Road Matchmaking Strategy [J]. Open Herald, 2017(5):84-87.

[7] Yu D, Peng L. When does Inferring Reputation Probability Countervail Temptation in Cooperative Behaviors for the Prisoners' Dilemma Game? [J]. Chaos, Solitons \& Fractals, 2015, 78: 238-244.

Aiping Zhou,female, (1972 -) associate professor, Jingdezhen Ceramic Institute,mainly engaged in public management research 